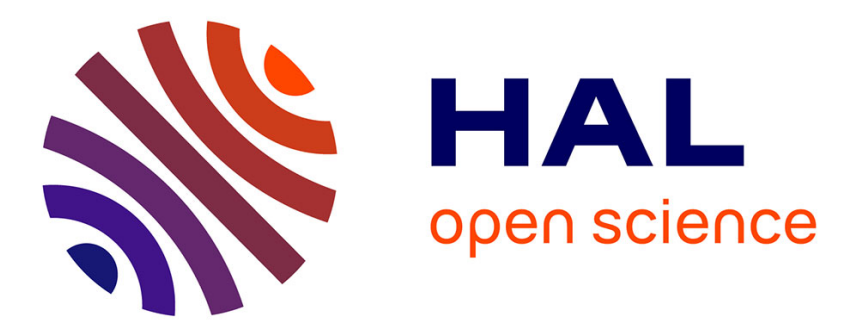

\title{
Controlling roughness: from etching to nanotexturing and plasma-directed organization on organic and inorganic materials
}

Evangelos Gogolides, Angeliki Tserepi, Vassilios Constantoudis, George Kokkoris, Dimitrios Kontziampasis, Katerina Tsougeni, George Boulousis, Marilena Vlachopoulou

\section{To cite this version:}

Evangelos Gogolides, Angeliki Tserepi, Vassilios Constantoudis, George Kokkoris, Dimitrios Kontziampasis, et al.. Controlling roughness: from etching to nanotexturing and plasma-directed organization on organic and inorganic materials. Journal of Physics D: Applied Physics, 2011, 44 (17), pp.174021. 10.1088/0022-3727/44/17/174021 . hal-00613279

\section{HAL Id: hal-00613279 https://hal.science/hal-00613279}

Submitted on 4 Aug 2011

HAL is a multi-disciplinary open access archive for the deposit and dissemination of scientific research documents, whether they are published or not. The documents may come from teaching and research institutions in France or abroad, or from public or private research centers.
L'archive ouverte pluridisciplinaire HAL, est destinée au dépôt et à la diffusion de documents scientifiques de niveau recherche, publiés ou non, émanant des établissements d'enseignement et de recherche français ou étrangers, des laboratoires publics ou privés. 


\title{
Controlling roughness: From etching to nanotexturing and plasma directed organization on organic and inorganic materials
}

Evangelos Gogolides*, Angeliki Tserepi, Vassilios Constantoudis, George Kokkoris, Dimitrios Kontziampasis, Katerina Tsougeni, George Boulousis, Marilena Vlachopoulou Institute of Microelectronics, NCSR "Demokritos", Terma Patriarhou Gregoriou St. Aghia Paraskevi, Attiki, Greece 15310

\begin{abstract}
We describe how plasma-wall interactions in etching plasmas lead to either random roughening / nanotexturing of polymeric and Silicon surfaces, or formation of organized nanostructures on such surfaces. We conduct carefully designed experiments of plasma-wall interactions to understand the causes of both phenomena, and present Monte-Carlo simulation results confirming the experiments. We discuss emerging applications in wetting and optical property control, protein adsorption, microfluidics and lab-on-a-chip fabrication and modification, and cost-effective silicon mold fabrication. We conclude with an outlook on the plasma reactor future designs to take advantage of the observed phenomena for new micro and nanomanufacturing processes.
\end{abstract}

\section{Introduction}

Lithography followed by plasma etching is the main top-down approach for micro and nanopatterning. Usually, during plasma etching ions "enhance" the removal of matter by neutrals and induce etch anisotropy (i.e. etching proceeds only towards the direction of impinging ions, which are accelerated perpendicularly to the substrate). However, microelectronic material etching has suffered for years from the so-called "grass" formed on plasma etched surfaces: The existence of any unetchable residues on the surface (or inside the material being etched) and the etch anisotropy lead to columnar nanostructure formation (grass), the column being protected by the unetchable material. Scanning-electronmicroscope (SEM) images of grass among structures are standard textbook material of etching problems in microelectronics fabrication classes.

On the other hand, grass may be seen as simply nanoroughness, or as desired nanotexture of a surface to be exploited for several applications. For example, if such a rough surface is coated with a low-surface-energy-film an increase in hydrophobicity will be observed leading to dramatic increases of the contact angle of water and oils (1) (2), (3), and eventually to a surface on which liquids roll, thus permitting self-cleaning action (4), (5) (6) of the surface. Another example where nanotexture is beneficial is when antireflectivity is desired: Etch-induced nanoroughness is known to reduce reflectivity for both $\mathrm{Si}$ (the "black Silicon" being a well known example (7)) and polymers for which the so called "nanomotheye" plasma roughening has been proposed (8). In fact for polymers plasma nanotexturing can simultaneously achieve optical transparency, antireflectivity and superhydrophobicity $(1,9)$. We would therefore like to emphasize that contrary to the undesirable effects of "grass" for nanoelectronics, controlled nanotexture formation may be valuable for nanomanufacturing of both large areas as well as devices, when one or more "smart" functionalities may be desired (10) . As the Greeks would say "there is no bad thing without a good side-effect", in other words one should not always cut the grass but rather control its growth.

Despite the fact that during plasma nanotexturing one is removing material, the result is the formation of grass-like nanostructures on the etched surface. This implies that plasmas may be used for the assembly of nanostructures even when used in the "subtractive-etching mode". The subtractive mode has been used to create nano-grass on polymers (1) (2), (3), to form nanocolums after random deposition of metallic etch inhibitors on the surface and subsequent etching (11), and recently to create Silicon nanotips and silicon nano-grass in Hydrogen /Argon mixtures $(12,13)$. Using the "additive mode" on the other hand, several 
groups have also demonstrated assembly of random nanostructures from depositing plasmas. In fact silicon and other inorganic material nano-grass growth by plasmas is a very active field as evidenced by several publications (14), (15), (16-18) including a recent review (19). Plasma has thus been proven to direct the assembly of both inorganic nanostructures(20), (19), and organic nanostructures (1),(2), while it has been claimed that plasma nanofabrication mimics nature in the creation of the cosmos (21). Thus, additive or subtractive plasma directed assembly emerges as a new field, under the broad title plasma nanoscience.

However, in all the above plasma directed assembly efforts pattern order and periodicity have not been looked at in detail or are missing as random patterns are formed. An exception to this rule has been the organization of parallel ripples on stressed or lithographed poly(dimethyl)siloxane (PDMS) films (22),(23) upon plasma oxidation. However, the formation of organized structures is often more desirable than random ones. For example, fabrication of organized, periodic nanodot, nanocolumn or nanopore arrays on surfaces is extremely useful in many fields ranging from biology, to hard disk drives, and from catalysis to photonics. Typically such structures are made with: a) either expensive nano-lithography (such as immersion, electron beam, Extreme Ultra Violet, or nanoimprint lithography) followed by smooth anisotropic plasma etching, b) self-assembly processes using block copolymers or colloidal nanospheres (24-27), which define an organized pattern usually on an intermediate polymeric layer, subsequently transferred to the substrate with smooth, anisotropic plasma etching $(21,27)$.

Very recently we have demonstrated that plasma etching alone can be used for plasma directed organization to BOTH create the organized nanodot pattern on any nonspecialty commercial polymer, and then transfer it to the substrate (28) (29). This finding has promoted plasma etching, an inherently top-down technology also as a bottom-up nanomanufacturing tool. The duality of plasma etching (i.e. create and transfer the pattern) is indeed unique, and may change the way we have been doing nanofabrication. Additionally it has added the dimension of plasma directed organization in the plasma nanoscience toolbox. To our knowledge only ion beam etching has up to now led to ion-beam directed organization, as nicely reviewed in several recent papers (30-32). It is the authors' opinion that despite the "cleaner" environment of ion beams, plasmas offer more opportunities and mechanisms due to chemical and physical synergies, and are inherently more cost-effective. Thus, plasma directed assembly and plasma directed organization are very promising emerging fields with a wealth of applications, modes (additive or subtractive), and materials to act upon.

It is the purpose of this progress and perspective paper to focus on plasma nanotexturing and plasma directed organization using mainly etching chemistries, i.e. a subtractive approach. This is to be complemented by the approaches of other groups which use mainly additive processes (19). We would like to encourage however our colleagues using depositing plasmas to look into the issue of nanostructure organization, as conditions may exist, where order is achieved. We believe that the phenomena we describe are generic, despite the fact that they are applied mostly for etching plasmas. Our approach in assembling nanostructures is twofold: either to do so, on a surface from which material is removed, thus ensuring that the nanostructures are of the same nature as the surface being etched, or to use a sacrificial soft (usually polymer layer) for the nanostructure assembly, and then transfer the pattern to an underlying substrate. Crucial for all the above is the plasma-wall interaction and this will be the focus of this paper.

Before moving on it is good to clarify some terminology. We have been using the terms plasma nanoroughening, plasma nanotexturing, and plasma directed assembly with no difference to denote random nanostructure creation, although nanotexturing could be used more appropriately for soft materials, and plasma directed assembly is a rather broader term initially used for depositing plasmas. To refer to organized structure formation we will be using the term plasma directed organization or simply plasma organization.

\section{What is different in plasma nanotexturing and plasma organization?}


In the subtractive mode of patterning the main action is removal of material using typically plasma etching of selected areas of a substrate. While the main action is etching, a very small amount of co-deposition is also taking place. In general co-deposition is so small that it goes by unnoticed in most plasma etching processes. This co-deposition may typically come from sputtering of unetchable materials from the metallic or dielectric reactor wall (we call these "hard" etch inhibitors(33)), from depositing material from the gas phase species, or from etchable wall materials (we call these "soft" inhibitors(33)) as shown schematically in figure 1. Normally all such co-depositing species would cause some type of "grass" formation after prolonged etching, if some etch anisotropy is present. As we have shown, such codeposition may lead to the so called roughness instability, i.e. almost linear increase of roughness with time (33). However, the role of the etch inhibitors is not limited to the roughness instability. Experimental results (29) show that ordered periodic morphologies can be induced on plasma etched polymeric surfaces. Thus, what is different in plasma directed assembly and organization is that the control of the ratios of ions/neutrals/inhibitors as well as the selectivities and etching yields allows control of the order, the height, and the spacing of the formed nanostructures.

Several recent studies address the problem of plasma roughening of polymers and its growth kinetics and most of them attempt its minimization in order to produce smooth etching for the nanoscale (34). However, rather than trying to suppress the appearance of plasma instability we have been allowing its formation in order to use it for several applications as will be discussed below, especially by tuning the geometry and the order of the assembled nanostructures (10).

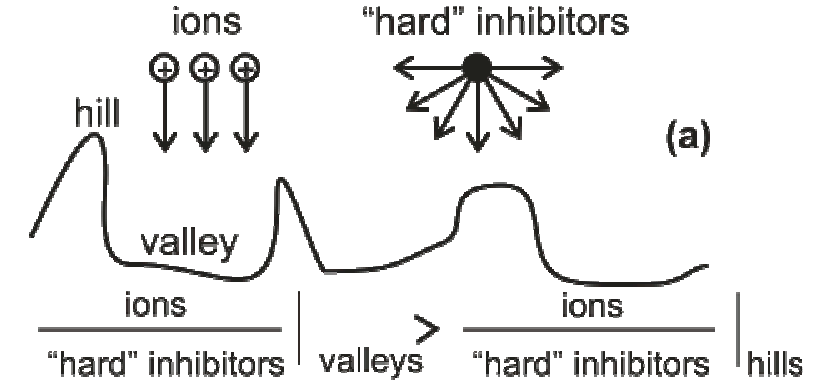

reactive neutrals (RN) "soft" inhibitors (SINH)

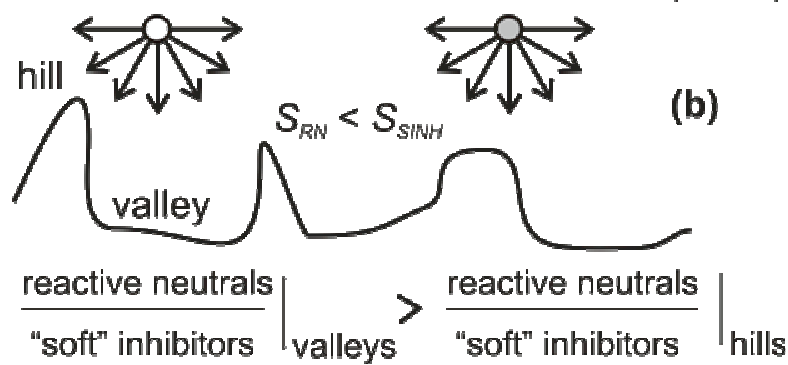

Figure 1. Two mechanisms(33) for plasma nanotexturing and roughness instability (i.e. linear growth of roughness with time). The arrows indicate the angular distribution of impinging species. a) Mechanism with "hard" inhibitors coming from reactor walls or electrode: The ratio of ions to inhibitors is higher in the valleys than on the hills, due to more intense shadowing of inhibitors compared to the ions. b) Mechanism with "soft" inhibitors: The ratio of reactive neutral species to inhibitors is higher in the valleys than on the hills, due to the lower sticking probability of reactive neutral species $\left(S_{R N}\right.$ $\left.<S_{S I N H}\right)$.

\section{Plasma Nanotexturing and the role of reactor walls}

We begin with a brief description of what plasma nanotexturing actually is. When a polymer surface is etched and a few microns of material have been removed, nanotexture may develop on its surface, and roughness may increase linearly with time. This is shown in figure $2 \mathrm{a}$ for two organic polymers Poly(methyl methacrylate) PMMA, and Poly(ether ether ketone) PEEK. Starting from a flat surface, within minutes one can get a rough surface, and finally a porous rough layer. X ray photoelectron Spectroscopy (XPS) analysis shown in figure $2 b$, reveals relatively large surface concentration of Aluminum present in Oxide form (35) coming from sputtering of the Alumina dielectric dome, and the anodized Aluminum 
clamping ring of the etch tool. This "hard" etch inhibitor creates micromasking and leads to the development of nanotexture. In nanoscience terminology the plasma directs the assembly of a rough nanotexture on the top surface of the polymer.
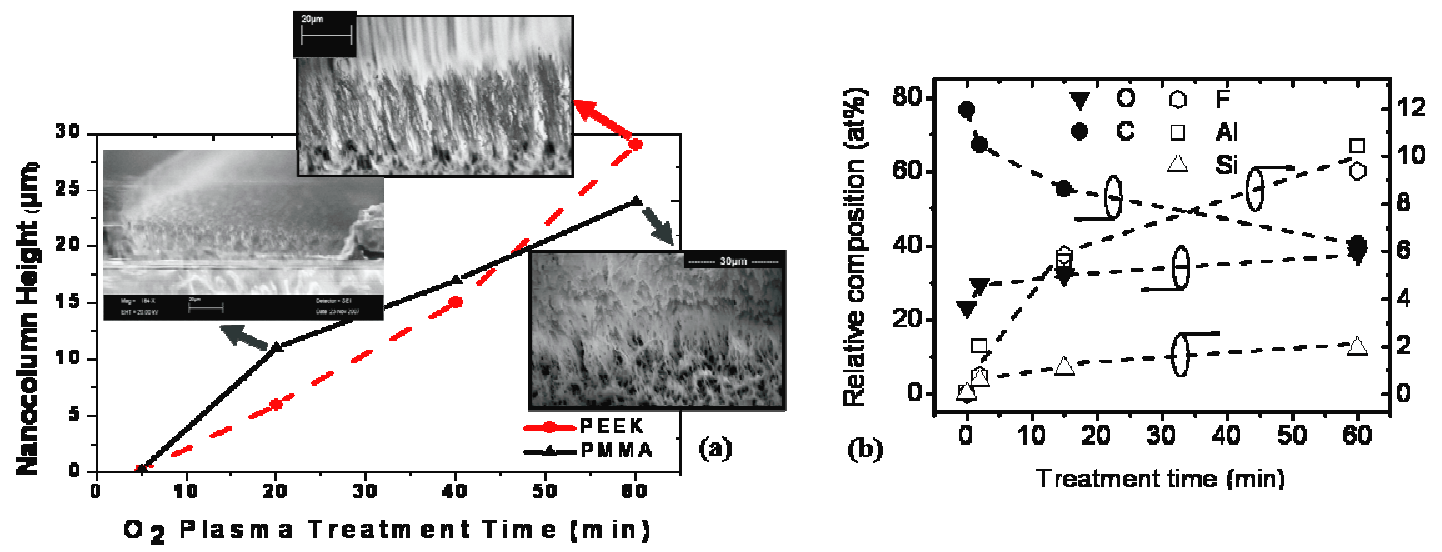

Figure 2. (a) Column Height on Micro and Nanotextured PMMA and PEEK plates in Helicon Plasma Reactor with Oxygen Plasma. The SEM images are shown embedded for selected times to reveal the porous surface formed. (b) Elemental XPS analysis of $0.5 \mathrm{~mm}$ thick PMMA plate versus etching time. Notice the large surface concentration of Aluminum. The reactor dome was made from alumina (35).

The XPS results suggest that nanotexture is a result of plasma-wall interactions. We thus decided to study how the phenomenon may be controlled by changing reactor wall material, and plasma reactor design. In this section we compare for the first time 7 different reactor wall conditions and their effects on the morphology of 3 representative materials, namely PMMA-a typical organic polymer-, PDMS-a typical inorganic polymer-, and Silicon-a typical inorganic material. Five out of the seven reactor conditions refer to different wall conditions of one reactor type, namely the MET system by Adixen-Alcatel. The two remaining conditions refer to an ICP etcher developed by Oxford Plasma Technology (OIPT).

The Adixen reactor is a helicon type reactor with an antenna of one loop around a dielectric (alumina) dome. The etching conditions in the Adixen tool were:

a) PMMA etch: $-100 \mathrm{~V}$ bias, $10^{\circ} \mathrm{C}, 0.75 \mathrm{~Pa}, 1900 \mathrm{~W}, 100 \mathrm{sccm} \mathrm{O}$, PMMA etch rate $1000 \mathrm{~nm} / \mathrm{min}$ (for plates), $1659 \mathrm{~nm} / \mathrm{min}$ (for films).

b) PDMS etch: $-100 \mathrm{~V}$ bias, $15^{\circ} \mathrm{C}, 1.33 \mathrm{~Pa}, 1900 \mathrm{~W}, 200 \mathrm{sccm} \mathrm{SF} 6$, PDMS etch rate $0.75 \mu \mathrm{m} / \mathrm{min}$

c) $\mathrm{Si}$ etch: $-55 \mathrm{~V}$ bias, $15^{\circ} \mathrm{C}, 5.25 \mathrm{~Pa}, 1800 \mathrm{~W}, 172 \mathrm{sccm} \mathrm{SF}$, Silicon etch rate $5 \mu \mathrm{m} / \mathrm{min}$. The conditions were chosen to be identical to the etching step of the gas chopping ("Bosch") process.

The OIPT reactor is an ICP with alumina dome having dielectric shielding, and a quartz clamping ring. The etching conditions in the OIPT reactor are described below and were chosen so as to achieve similar etching rates with the Adixen tool:

a) PMMA etch: $-105 \mathrm{~V}$ bias, $5{ }^{\circ} \mathrm{C}, 0.74 \mathrm{~Pa}, 1000 \mathrm{~W}, 50 \mathrm{sccm} \mathrm{O}_{2}$, PMMA etch rate $1194 \mathrm{~nm} / \mathrm{min}$ for films

b) PDMS etch: $-100 \mathrm{~V}$ bias, $15^{\circ} \mathrm{C},, 1000 \mathrm{~W}, 200 \mathrm{sccm} \mathrm{SF}_{6}$, PDMS etch rate $0.7 \mu \mathrm{m} / \mathrm{min}$

c) Si etch: - $55 \mathrm{~V}$ bias, $5^{\circ} \mathrm{C}, 5 \mathrm{~Pa}, 1800 \mathrm{~W}, 172 \mathrm{sccm} \mathrm{SF} 6$, Si etch rate $10 \mu \mathrm{m} / \mathrm{min}$

The 7 wall conditions were the following:

- Wall condition 1 (Alumina dome, Anodized Al ring, Helicon source) briefly referred to as (Alumina, Anodized Al, Helicon) refers to clean alumina dome and anodized aluminum clamping ring of the Adixen Helicon System.

- Wall condition 2 (Polymer, Polymer, Helicon) refers to covering (painting with a brush) the interior of the dome of the Adixen Helicon System with photoresist polymer, (especially in the area of high RF fields close to the antenna), and painting 
the anodized aluminum ring also with photoresist (see figure 3a). Both surfaces were baked after being painted with photoresist polymer.

- Wall condition 3 (Polymer, Anodized Al, Helicon), refers to painting only the dome area and NOT the anodized aluminum ring of the Adixen Helicon System (see figure 3a).

- Wall condition 4 (Alumina, Polymer, Helicon), refers to painting only the anodized aluminum ring and not the reactor dome of the Adixen Helicon System (see figure 3a).

- Wall condition 5 (Quartz, Al, Helicon), refers to using an identical Adixen Helicon System with quartz dome and aluminum ring (not anodized).

- Wall condition 6 (Alumina, Quartz, ICP, Shield), refers to using an ICP reactor from OIPT, with quartz dome, and quartz ring, and having electrostatic shielding of the RF fields to minimize dome material sputtering.

- Wall condition 7 (Alumina, Quartz, ICP, No Shield), refers to using an ICP reactor from OIPT without electrostatic shielding of the RF dome.

Figure 3 shows several characteristic results from the 7 conditions used for the etching of PMMA plates. Figure $3 \mathrm{~b}$ shows an SEM picture of a PMMA film etched for 2 min in the helicon reactor (etch depth $3.4 \mu \mathrm{m}$ ). A columnar morphology is clearly seen on the film after etching. Figure $3 \mathrm{c}$ shows how the morphology is influenced by changing the dome material from alumina to quartz; Instead of columns nanomounds are now observed with height values less (approximately half) than those of the nanocolumns shown in figure $3 \mathrm{~b}$, as AFM measurements reveal (see also Table 1). Similar results are observed not only for films, but also for commercial PMMA plates, as shown in figure 3d,e,f. Indeed, after 1min of etching (more than $2 \mu \mathrm{m}$ of etched depth) severe micro and nanotexture appears on the surface of the plate and the root mean square (rms) roughness jumps to more than 40nm (figure 3d). Plasma etching directs the assembly of "grass" like micro-nanocolumns on PMMA as a result of Alumina sputtering and micromasking. Figure $3 \mathrm{~d}$ is the AFM version of figure $3 \mathrm{~b}$ but for a plate rather than a film and for only 1 min etching. When painting the dome and ring of the reactor with a photoresist polymer, roughness is halved (figure 3e), and the morphology of the assembled nanostructures changes from grass-like to nanomounds, suggesting a transition from hard inhibitors (sputtered $\mathrm{Al}$ compounds from the reactor walls) to soft inhibitors (sputtered/partially etched photoresist polymer from the covered reactor wall). We note that this change is not accompanied by any significant etch rate reduction. In the OIPT reactor, an etching system designed for minimized sputtering and equipped with electrostatic shielding, roughness is only $4.5 \mathrm{~nm}$ even after $2 \mathrm{~min}$ of etching (figure $3 \mathrm{f}$ ), i.e. is reduced by an order of magnitude, resulting in relatively smooth surfaces.
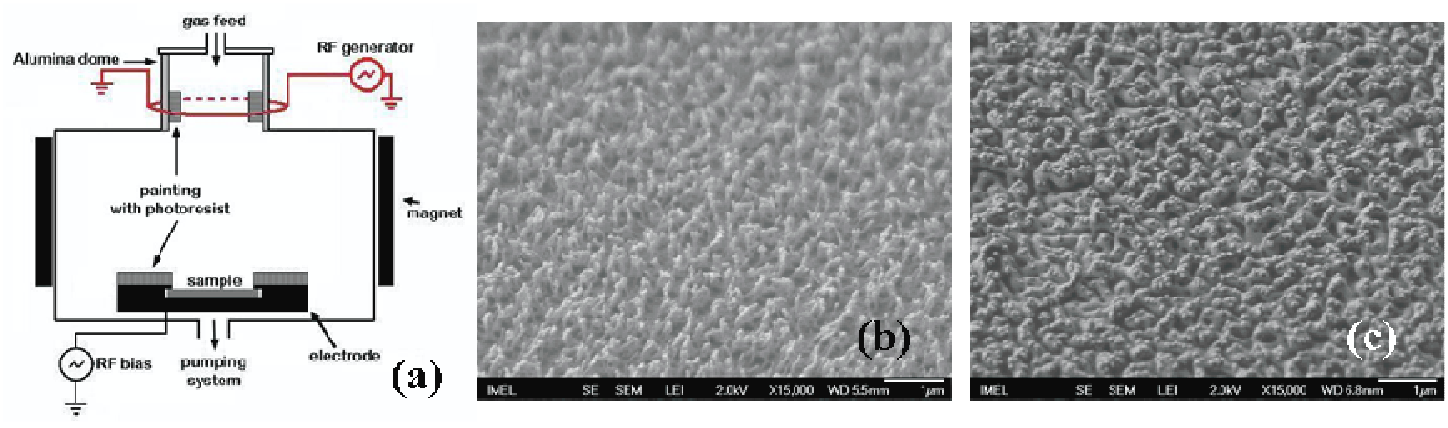

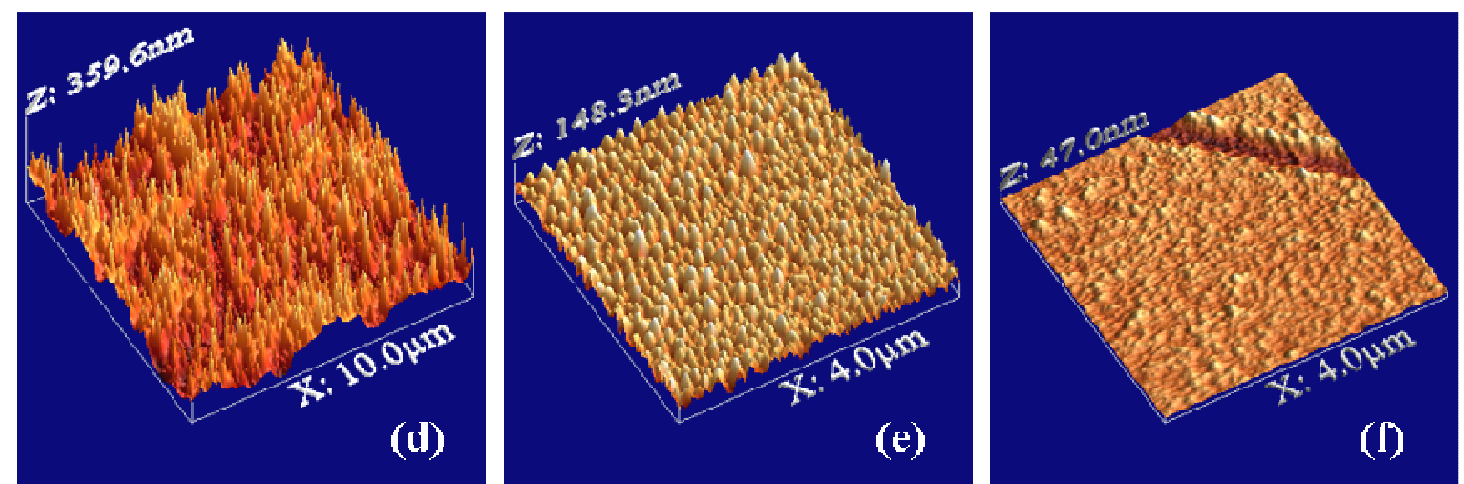

Figure 3. Plasma nanotexturing of PMMA in $\mathrm{O}_{2}$ and the role of reactor walls. For the complete set of experiments refer to Table I. The z axis shows the range of height values in each image.

(a) Schematic of the MET Helicon reactor showing the positions of painting with photoresist polymer the walls in order to reduce wall material sputtering.

(b) Wall condition 1 for PMMA film etched for 2min. The SEM image shows the morphology of a polymer film and the roughness formed.

(c) Wall condition 5 for PMMA film etched for $2 \mathrm{~min}$. Conditions are the same as in figure 3b, the main difference being that the dielectric dome material is quartz rather than Alumina.

(d) PMMA plate etching at condition 1: Alumina dome and clamping ring with anodized aluminum. Scan size: $10 x 10 \mu m$, Treatment time: 1 min Rms: $41.8 \mathrm{~nm}$.

(e) PMMA plate etching at condition 2: Photoresist on the ring and in the dome (only the antenna area). Treatment time: Imin, Scan size: $4 x 4 \mu \mathrm{m}$. Rms: $23.7 \mathrm{~nm}$.

(f) PMMA plate etching at condition 7, Without Electrostatic Shielding of the RF field of the antenna, Treatment time: $2 \mathrm{~min}$, Scan size: $4 x 4 \mu \mathrm{m}$. Rms: $4.5 \mathrm{~nm}$.

Note: AFM images were processed using the Software WSxM(36)

Figure 4 shows characteristic etching results of PDMS (an inorganic polymer) with $\mathrm{SF}_{6}$ plasma. In a reactor with alumina dome and ring, etching for just two minutes leads to roughness value of approximately $100 \mathrm{~nm}(\mathrm{rms})$ as shown in figure $4 \mathrm{a}$. After painting both the ring and the dome with an organic polymer roughness drops by more than an order of magnitude to only $8.7 \mathrm{~nm}$ (figure $4 \mathrm{~b}$ ). When only the dome is covered with a polymer, while the anodized aluminum ring is exposed to the plasma, roughness increases slightly, but still remains at low values of $11.6 \mathrm{~nm}$. It is also extremely interesting to see that when changing the dome from Alumina to quartz, which is etched by the $\mathrm{SF}_{6}$ plasma, roughness remains to low levels. Thus for PDMS etching the main contributor for roughness formation is the sputtering of alumina (in the form of Aluminum oxyfluoride) from the dome to the sample, a result also observed for Silicon etching by others (37).
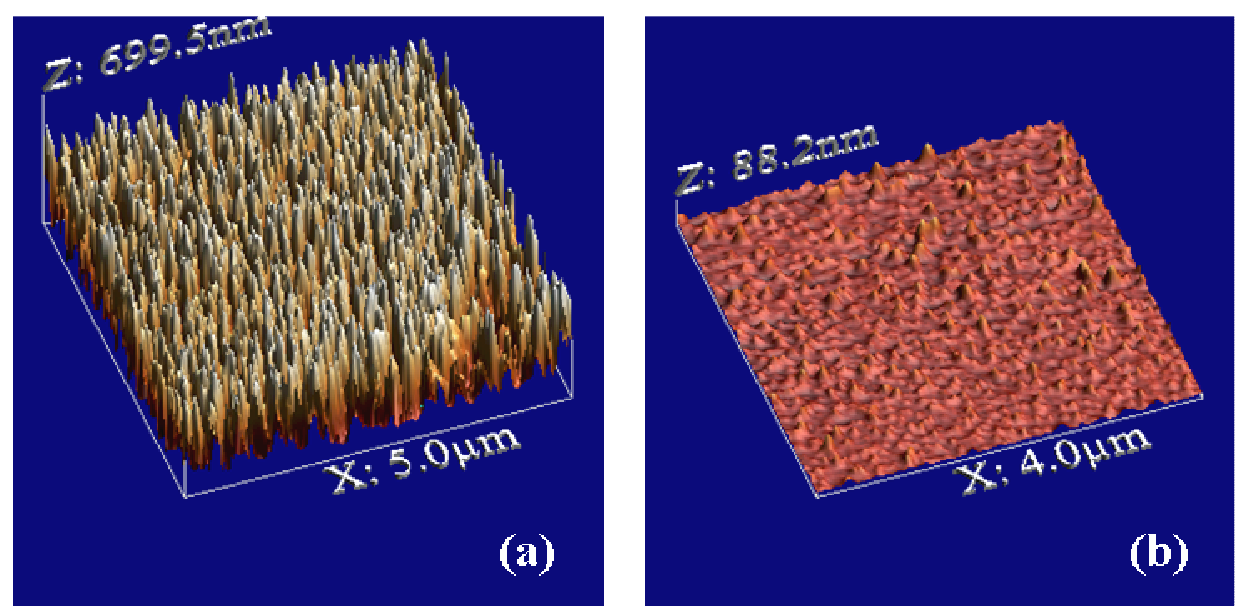

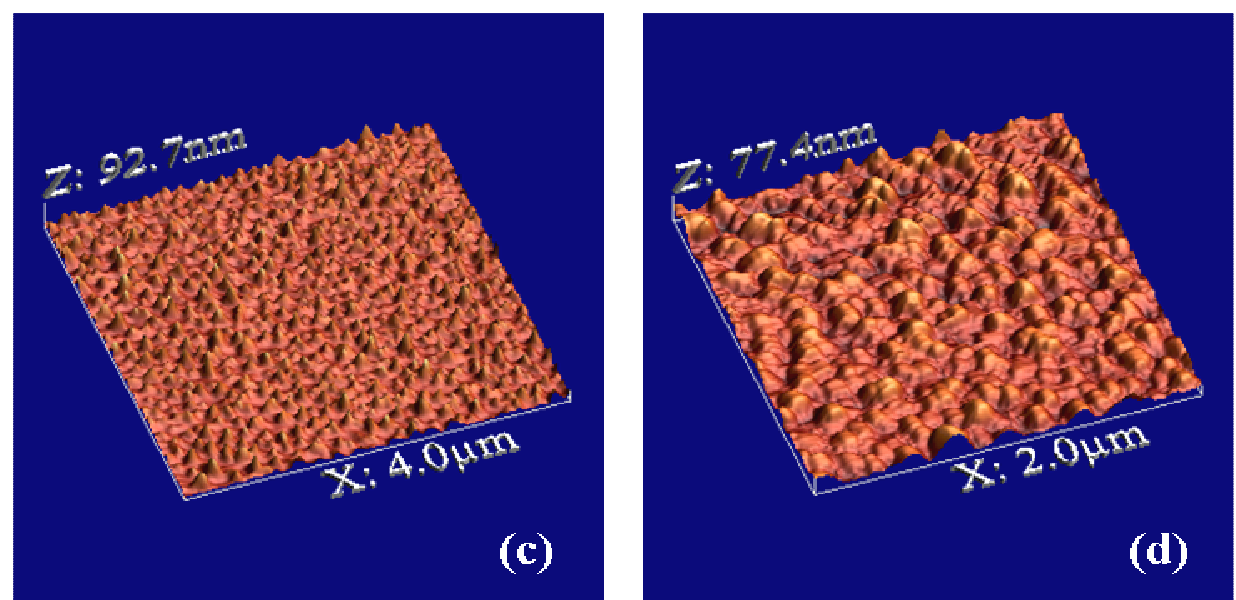

Figure 4. Plasma Nanotexturing of PDMS in $S_{6}$ and the role of reactor walls. For the complete set of experiments refer to Table I. The z axis shows the range of height values in each image.

(a) PDMS etching in $S F_{6}$ for 2 min at wall conditions 1 , rms $=98 \mathrm{~nm}$.

(b) PDMS etching in $S_{6}$ for 2 min at wall condition $2, \mathrm{rms}=8.7 \mathrm{~nm}$.

(c) PDMS etching in $S_{6}$ at wall condition 3, rms=11.6nm.

(d) PDMS etching in $\mathrm{SF}_{6}$ at wall condition $5 \mathrm{rms}=11.2 \mathrm{~nm}$.

Finally experiments were done also for an inorganic material (Silicon) which is etched mostly isotropically and for which grass formation is not justified on the grounds of anisotropy. Figure 5a shows that after etching silicon in $\mathrm{SF}_{6}$ plasma for $4 \mathrm{~min}(20 \mu \mathrm{m}$ etch depth) rough nanomounds appear (38) with rms value of $9.3 \mathrm{~nm}$. When the dome and ring are covered with photoresist, roughness values drop by almost 4 times (Figure $5 \mathrm{~b}$ ). When moving to the OIPT system even without an electrostatic shield roughness is further reduced as seen in Figure 5c.
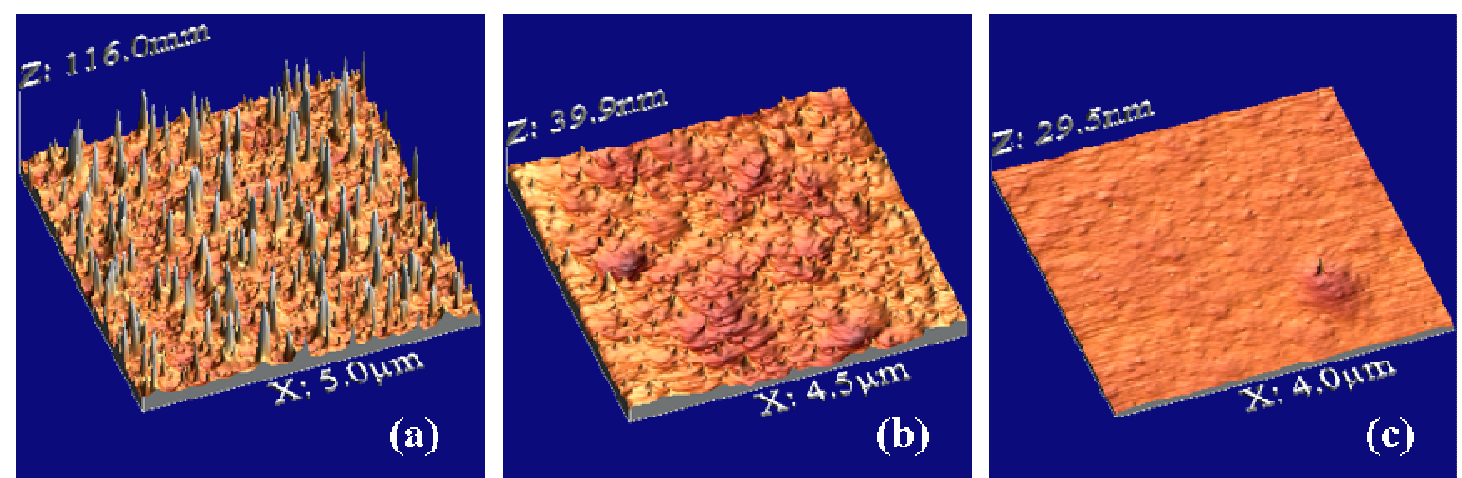

Figure. 5. Plasma Nanotexturing of Silicon in $\mathrm{SF}_{6}$ and the role of reactor walls. For the complete set of experiments refer to Table I. The z axis shows the range of height values in each image.

(a) Silicon etching for 4 min in SF6 at wall condition 1, rms $=9.3 \mathrm{~nm}$.

(b) Silicon etching for 4 min in SF6 at wall condition 2, rms $=2.5 \mathrm{~nm}$.

(c) Silicon etching for $4 \mathrm{~min}$ in SF6 at wall condition $7 \mathrm{rms}=1 \mathrm{~nm}$.

The complete set of experiments is summarized in Table I below. Some remarks and observations can be made by looking at figures 3,4,5 and roughness values shown on Table I:

First, one can note that the substrate / etch chemistry combination is crucial for roughness formation: For Silicon despite etching for 20micrometers roughness is below $10 \mathrm{~nm}$, while for polymers roughness can be one order of magnitude higher for an etch depth of only 2 micrometers.

Second, one can observe that the reactor design is crucial for roughness / nanotexture formation. The ICP reactor with the larger dome diameter results in smooth surfaces (compare condition 1 to condition 6 and 7). Even the absence of electrostatic shielding of the 
RF fields does not significantly increase roughness (compare conditions 6 and 7), which is one order of magnitude less compared to the unshielded helicon system.

Third, one may notice that in the helicon reactor covering the wall with polymer eliminates any sputtering of wall material (hard inhibitors) and results in almost one order of magnitude decrease of roughness down to values comparable to those of the OIPT system. The roughness reduction is larger for PDMS compared to Silicon and PMMA. Polymeric walls are of course also sputtered or etched and result in soft inhibitors. These are etched more easily thus reducing or eliminating nanotexture. The intermediate wall conditions of the Helicon reactor (see conditions 3 and 4) result in intermediate roughness, suggesting that both sputtering of the dome and the ring material is responsible for roughness formation, with the dome having a more important role.

Fourth, one understands that the chemical interaction of wall materials with the plasma is also crucial in achieving or eliminating roughness. For example in the Helicon reactor a drastic decrease (by a factor of more than 3) of nanotexture of PDMS surfaces occurs when the Alumina dome is painted with photoresist (condition 2). In addition, changing the dome to quartz, or painting the alumina ring (condition 4) results in significant reduction of nanotexture. In condition 2 the plasma interacts with a "polymeric" walls and any sputtered material is etchable (soft inhibitor). The same is partially true for condition 5, where the dome is made from quart a material etchable (but with smaller etching rate compared to polymer) in the SF6 plasma; As a result both conditions 2 and 5 reduced roughness. Thus, a good method to nanotexture PDMS is by having unetchable sputtered material (e.g. Alumina) in the SF6 plasma. Reversing the argument one could say that the only way to have smooth PDMS etching is by using quartz or carbonaceous walls, and a system designed for minimal sputtering; Indeed, note that the OIPT system which gives the smoothest PDMS surfaces (see Table I) has a quartz (etchable) ring and an antenna shielding minimizing sputtering of the Alumina dome.

Finally, we again stress that appropriate reactor design and wall material selection are the main parameters to reduce roughness if that is desired. On the other hand production of smart superhydrophobic surfaces with random nanotexture necessitates controlled wall material sputtering during etching (39).

Table I. Effect of reactor wall condition and reactor type on rms roughness of nanotextured polymeric and Silicon surfaces. The numbers given are the RMS roughness in $\mathrm{nm}$, while the etch rate is indicated in parenthesis in $\mu \mathrm{m} / \mathrm{min}$ so that the etch depth can be calculated. ( $\mathrm{n} / \mathrm{m}$ stands for not measured)

\begin{tabular}{|c|c|c|c|c|c|c|c|}
\hline $\begin{array}{l}\text { Wall condition } \\
\text { (ddme } \\
\text { clamping ring } \\
\text { Reactor ype) } \\
\text { Substrate }\end{array}$ & $\begin{array}{l}\text { Alumina } \\
\text { anod-Al } \\
\text { Helicon } \\
1\end{array}$ & $\begin{array}{l}\text { Polymer } \\
\text { Polymer } \\
\text { Helicon } \\
2\end{array}$ & $\begin{array}{l}\text { Polymer } \\
\text { Anod. Al } \\
\text { Helicon } \\
3\end{array}$ & $\begin{array}{l}\text { Alumina } \\
\text { Polymer } \\
\text { Helicon } \\
4\end{array}$ & $\begin{array}{l}\text { Quartz } \\
\text { Al } \\
\text { Helicon } \\
5\end{array}$ & $\begin{array}{l}\text { Alumina } \\
\text { Quartz } \\
\text { ICP e-shield } \\
6\end{array}$ & $\begin{array}{l}\text { Alumina } \\
\text { Quartz } \\
\text { ICP No e-shield } \\
7\end{array}$ \\
\hline \multirow{3}{*}{$\begin{array}{l}\text { PMMA plate } \\
2 \text { min etch ( } \\
\text { some values } \\
\text { for } 1 \text { and } 5 \\
\text { min etch) }\end{array}$} & $98(1)$ & $29(0.8)$ & \multirow[t]{3}{*}{$61(1)$} & \multirow[t]{3}{*}{$64(1)$} & \multirow[t]{3}{*}{41} & \multirow[t]{3}{*}{$3.7(0.75)$} & \multirow[t]{3}{*}{$4.5(0.75)$} \\
\hline & 40 for $1 \mathrm{~min}$ & $\mathrm{n} / \mathrm{m}$ & & & & & \\
\hline & $\begin{array}{ll}240 & \text { for } \\
5 \mathrm{~min} & \\
\end{array}$ & $\begin{array}{ll}38 & \text { for } \\
5 \mathrm{~min} & \\
\end{array}$ & & & & & \\
\hline $\begin{array}{l}\text { PMMA film } \\
\text { 2min etch }\end{array}$ & $65(1.6)$ & $\mathrm{n} / \mathrm{m}$ & $\mathrm{n} / \mathrm{m}$ & $\mathrm{n} / \mathrm{m}$ & 13 (1.6) & $\mathrm{n} / \mathrm{m}$ & $\mathrm{n} / \mathrm{m}$ \\
\hline \multirow{2}{*}{$\begin{array}{lr}\text { PDMS } & \text { film } \\
(2 \mathrm{~min} & \text { etch, } \\
\text { some } & \text { values } \\
\text { for } & 1 \mathrm{~min} \\
\text { given) } & \\
\end{array}$} & $100(0.75)$ & $\begin{array}{l}3.4 \\
\text { average } \\
(1.1) \\
\end{array}$ & \multirow[t]{2}{*}{$11.6(0.85)$} & \multirow[t]{2}{*}{$12.4(0.85)$} & $11.2(1)$ & \multirow[t]{2}{*}{$1.6(0.7)$} & \multirow[t]{2}{*}{$1.4(0.7)$} \\
\hline & 25 for $1 \mathrm{~min}$ & $\begin{array}{ll}0.8 & \text { for } \\
1 \mathrm{~min} & \end{array}$ & & & $\begin{array}{ll}4.3 & \text { for } \\
1 \mathrm{~min} & \end{array}$ & & \\
\hline $\begin{array}{l}\text { Si wafer } 20 \mu \mathrm{m} \\
\text { etch depth } \\
(4 \mathrm{~min} \text { etch) }\end{array}$ & $9.1(5)$ & 2.4 & 2.9 & $\mathrm{n} / \mathrm{m}$ & $\mathrm{n} / \mathrm{m}$ & $1.1(10)$ & $1(10)$ \\
\hline
\end{tabular}




\section{Plasma Directed Organization and the role of reactor walls}

We start this section with a brief description of plasma directed organization on polymers. Under specific etching conditions nanotexturing may take the form of organized nanodots on a polymeric surface as shown in figure $6 \mathrm{a}$. The specific etching conditions used for obtaining the results shown in figure 6a were: PMMA film etched in Oxygen plasma, $0 \mathrm{~V}$ bias, $65^{\circ} \mathrm{C}, 0.75 \mathrm{~Pa}, 1900 \mathrm{~W}, \mathrm{O}_{2}$ flow $100 \mathrm{sccm}$, etch rate $1659 \mathrm{~nm} / \mathrm{min}$, wall condition 1 described in the previous section. Order and organization is witnessed by a peak in the Power Spectrum of the Surface as shown in figure $6 \mathrm{~h}$. The question therefore arises as to what is causing plasma directed organization.

Recent modeling results from our team (29) support the hypothesis that plasma directed organization is also due to fast etching of the polymer with simultaneous deposition of etch inhibitors from the plasma reactor walls. In this section we experimentally verify the role of plasma reactor walls on the formation of order and the assembly of organized nanodots. For these experiments both thin $(750 \mathrm{~nm})$ and thick $(5500 \mathrm{~nm})$ PMMA films were used, rather than plates as in the previous section. The etching time in most cases was $40 \mathrm{~s}$ and the other conditions were the same described above for figure 6 a. The 7 wall conditions were the same as those used for nanotexturing, with the exception that we did not perform experiments at wall condition 6 since the Helicon Reactor with the quartz dome did not support etching at $65{ }^{\circ} \mathrm{C}$. In addition, for the ICP reactor from OIPT an $8^{\text {th }}$ plasma-wall condition was used:

Wall condition 8 (Alumina, Quartz, ICP, Shield, photoresist carrier plate), refers to using an ICP reactor from OIPT, with alumina dome, and quartz ring, and having electrostatic shielding of the RF fields to minimize dome material sputtering. In addition the carrier 4 inch wafer was coated with a thick photoresist, and the samples were pieces (rather than whole wafers) covered with PMMA film and glued on the photoresist-coated carrier wafer. Figure 6 shows the AFM images of PMMA films etched with Oxygen plasma for different plasmawall conditions and the effects on plasma organization.
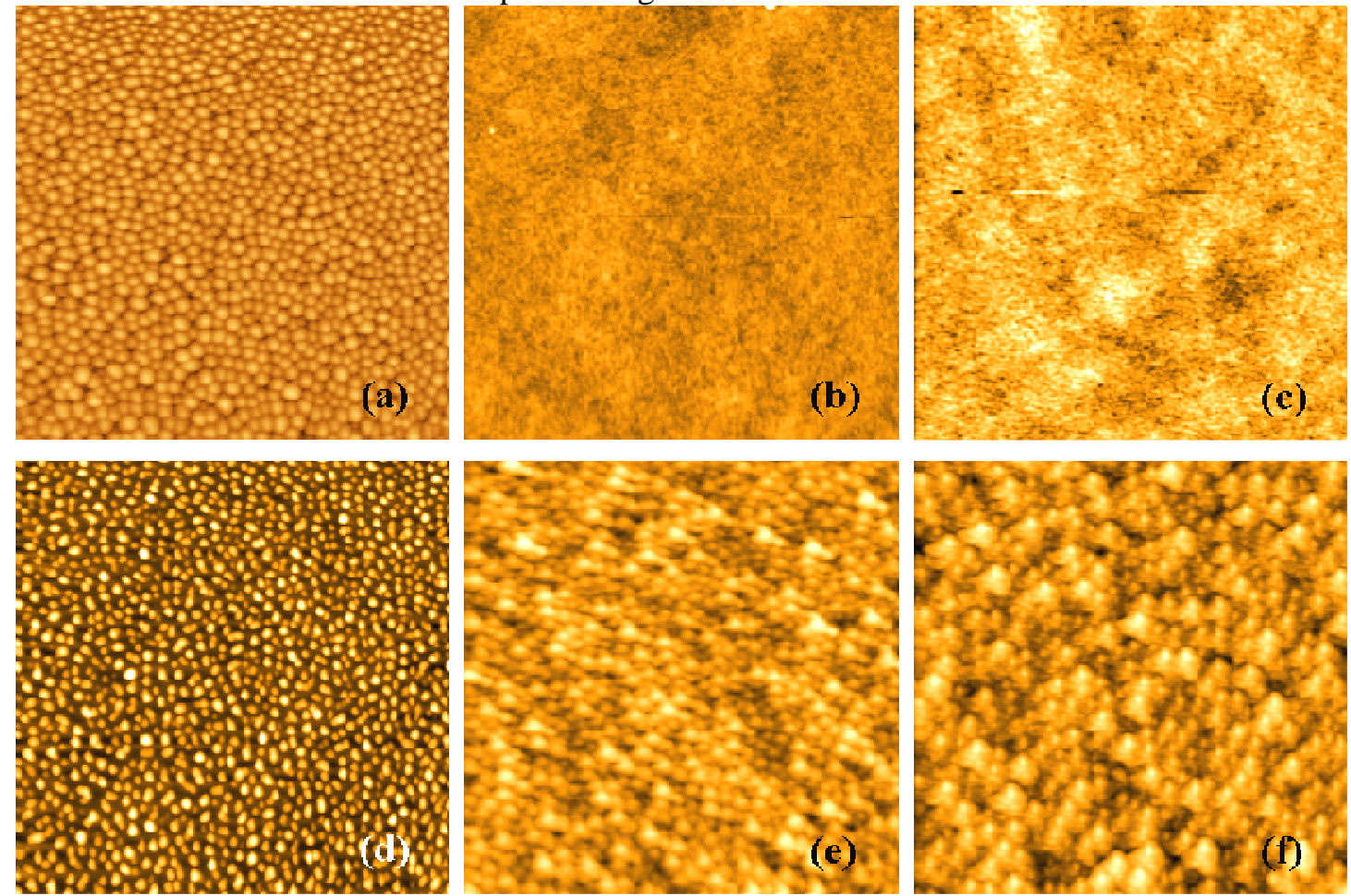

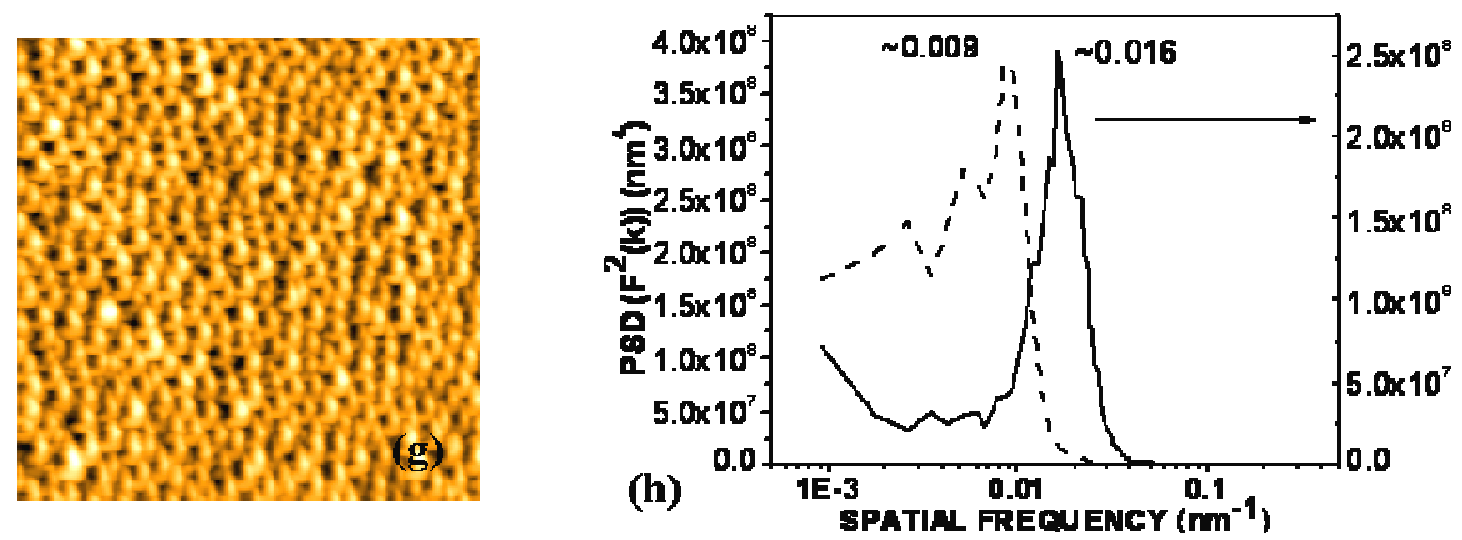

Figure 6. Plasma directed organization on PMMA film in $\mathrm{O}_{2}$ plasma and the role of reactor walls. AFM images $(2 \times 2 \mu \mathrm{m})$ are shown. Typical etch rates are $600 \mathrm{~nm} / \mathrm{min}$, while nanodot formation is observed only at certain wall conditions.

(a) Wall condition 1 (Alumina, Anodized Al, Helicon) ( $r m s=6.5 \mathrm{~nm}$, etch time 40s). Nanodot formation is evident.

(b) Wall condition 2 (Polymer, Polymer, Helicon) ( $r m s=0.3 \mathrm{~nm}$, etch time 40s). No nanodots are observed.

(c) Wall condition 3 (Polymer, Anodized Al, Helicon) ( $r m s=0.4 n m$, etch time 40s). No nanodots are observed.

(d) Wall condition 4 (Alumina, Polymer, Helicon) (rms=2.6nm, Etch time 15s only). Nanodots are formed even at $1 / 3$ of the etch time.

(e) Wall condition 6 (Alumina, Quartz, ICP, Shield, ) Rms: $1.5 \mathrm{~nm}$, Etch time 42s. Nanodots are not sharp, they are short and less periodic.

(f) Wall condition 7 (Alumina, Quartz, ICP, No Shield), Rms: $1.6 \mathrm{~nm}$, etch time: $42 \mathrm{sec}$, Nanodots are not sharp; they are short and less periodic.

(g) Wall condition 8 (Alumina, Quartz, ICP, Shield). Base plate (i.e. carrier of the sample) coated with thick layer of photoresist. Etch time 84s, rms=3.6nm.Nanodots are formed with slightly different morpholoby compared to figure $6 a$.

(h) PSD of the surfaces resulting from wall conditions 1 (figure 6a) and 8 (figure 6g). A peak indicative of the periodicity and organization is shown at wavenumbers of 0.016 and $0.009 \mathrm{~nm}^{-1}$, corresponding to $\lambda=63 \mathrm{~nm}$ and $116 \mathrm{~nm}$ respectively.

As one can see from figure 6, the nanodots formed on the PMMA film (figure 6a) disappear when the dome and the ring of the reactor are coated with photoresist (figure 6b) at least for the same etching time. This shows that by diminishing sputtering from the reactor one can prevent the creation of the nanodots. When only the dome of the reactor is coated with photoresist, the surface is similarly flat without nanodots (figure $6 \mathrm{c}$ ). We can thus clearly state that sputtering of the Alumina dome plays a major role in the creation of the nanodots. To strengthen our hypothesis we continued by coating only the ring and observed that we got back the nanodot formation on the PMMA surface even when etching for only 15s (the etch time used in almost all other experiments in the figure is 40s).

The next step was to use a different etching system an ICP etcher by OIPT in which the experimental conditions were altered so as to achieve the same etch rate as in the Adixen system. However, heating was not possible in the OIPT system. Figure 6e,f show characteristic results of these experiments. With or without electrostatic shielding the ICP has small random roughness. The nanodots are not totally absent, but they are diminished in size compared to the previous system (rms is $1.5 \mathrm{~nm}$ in OIPT and $6.5 \mathrm{~nm}$ in Adixen), while they lack in order, uniformity of shape and organization for the same etching time. However, at wall condition 8 (figure $6 \mathrm{~g}$ ) we used as samples pieces of PMMA coated wafers, and mounted these pieces on a carrier 4 inch Silicon wafer coated with a photoresist layer. To our surprise, we observed formation of ordered nanodots after $84 \mathrm{~s}$ of etching, which we attributed to etching and sputtering of the photoresist on the carrier wafer. Such sputtering of the organic photoresist is possible even at zero bias with the ions having the energy of the plasma 
potential. We thus have first evidence that even "soft" inhibitors can lead to plasma directed organization. It is however a puzzle why such "soft" inhibitor assisted organization was not observed in the Adixen system when covering the dome with photoresist. It may be that our etching time was too short to observe it, or that the amount of polymer was very large.

\section{Understanding plasma nanotexturing and plasma directed organization through simulation}

(1+1) Dimensional (33) and (2+1) Dimensional Monte Carlo simulations have been performed considering that the surface is represented by a $2 \mathrm{D}$ or $3 \mathrm{D}$ lattice and is subjected to fluxes of neutral etchants, ions, and soft or hard inhibitors (hard are those removed only by ions). The morphology, the roughness parameters, and the time evolution are recorded. Surfaces are analyzed with power spectra (PSD) and height-height correlation functions to derive the exponents of growth of the roughness parameters.

Figure 7 below shows an example of both the time evolution of rms roughness and surface morphology when anisotropic ion etching and isotropic deposition of hard inhibitors are considered. Roughness instability is observed in agreement to the experimental behaviour (see figure2a). Furthermore, such simulation results match very closely the AFM images obtained from anisotropic ion enhanced etching of polymers.

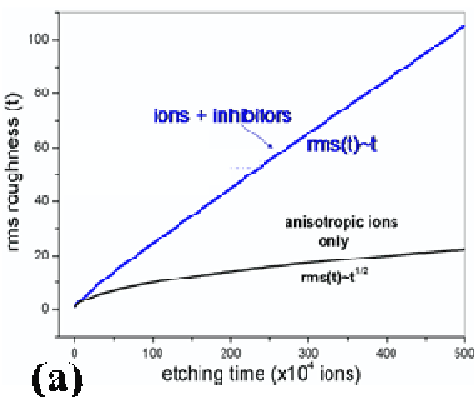

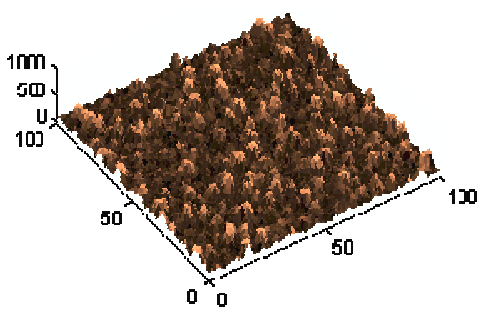

(b)

Figure 7. Monte Carlo Simulation of ion and hard inhibitor driven plasma roughening.

(a) Evolution of the rms roughness with time for assumed mechanism of hard inhibitors and ion enhanced etching. For the sake of comparison the rms increase due only to ions (without inhibitors) is also depicted.

(b) Simulation of the evolution of surface morphology with time (AFM-like images) when one considers anisotropic ion-enhanced etching, and isotropic deposition of hard inhibitors. The etching time increases from the left to the right, the fraction of depositing hard inhibitors is 0.05 and the selectivity of inhibitors vs. bulk material is 10. Notice the formation of columnar structures which are becoming higher, less dense and wider with time. Compare with AFM images for polymer etching and silicon in figures 3, 4, and 5 above.

Preliminary simulations have been also performed with a close look at the PSD of the surface, in order to see if there are cases where a peak is observed, indicative of order formation. The simulation results showed that the combination of non-reflecting ions, arriving at the surface at almost normal incidence and causing ion-enhanced etching, with a small amount $(<10 \%)$ of depositing soft inhibitors, may induce order on the etched surface. Figure $8 \mathrm{a}, \mathrm{b}$ shows a simulated surface in a $3 \mathrm{D}$ and $2 \mathrm{D}$ top down view which reveals a similarity with the experimental surface of figure $6 \mathrm{a}$. Figure $8 \mathrm{~b}$ shows embedded the circularly averaged PSD of the simulated surface, where the periodicity of the surface is manifested in the peak. Deposition alone has been reported to produce periodic mounds (40). Our case is codeposition during ion-enhanced etching and the mounds are not made by deposited inhibitors; indeed for the surface of figure 6 a, the surface coverage by depositing particles is only $10 \%$. 

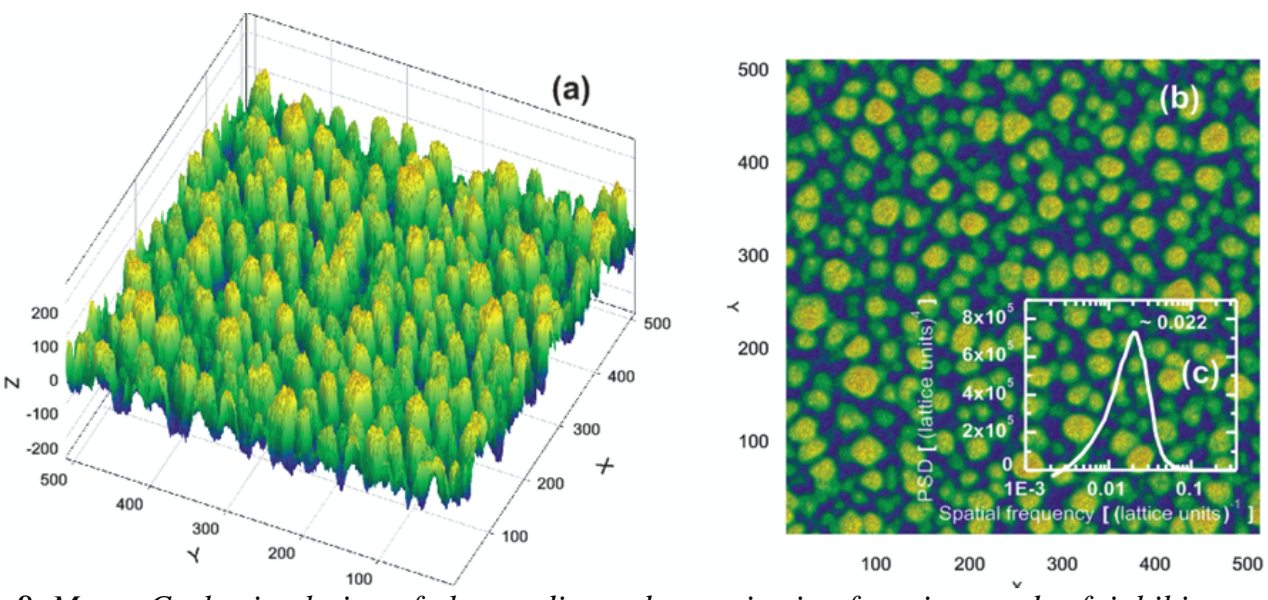

Figure 8. Monte Carlo simulation of plasma directed organization from ions and soft inhibitors. (a) 3D top-down view of a surface produced by the Monte Carlo simulator (3600 monolayers have been etched and the fraction of depositing inhibitors is 0.05). (29)

(b) Top-down view of the surface shown in figure 8 . Notice the similarity with figure 6a Average PSD of 10 simulated surfaces. The surface coverage by the depositing particles is only 0.1.

\section{Emerging Applications?}

\subsection{Control of surface wetting}

Control of wetting properties on all surfaces and especially on polymers is important in many technological applications. Some applications require the surface to be completely wetted, others require it to be totally water repellant. Plasma processing and plasma nanotexturing is an ideal tool to this extent since it allows control of both the surface chemistry and of the surface topography / texture. Oxygen plasma treatment of polymers produces superhydrophilic surfaces. While such surfaces usually show hydrophobic recovery, plasma nanotextured surfaces may withstand such recovery for a period of more than a month (35).

On the other hand the demand for self-cleaning, antifogging, and anti-icing behaviour poses a need for superhydrophobic surfaces (1), (2) (3), (4), (5) (6). Plasma nanotexturing combined with plasma deposition of low energy coatings is again an ideal technology. It was as early as 1993 (41) that formation of ultra hydrophobic glass surfaces was demonstrated taking advantage of the roughness formation during plasma processing, while analogous demonstrations have been made for polymers (polypropylene (42), PDMS (2),(3), PMMA (1),(3) and other polymers (43-46)). In addition Si nano-tips with low-energy overcoats (47) and carbon nanotubes without any additional overcoats (48) have been shown to have excellent superhydrophobic properties.

Figure 9a shows how nanotexturing of a polymer followed by thin fluorocarbon layer plasma deposition makes the polymer superhydrophobic. Examples are shown for PMMA and PDMS, two different polymers, the first being etched in oxygen and the second in sulfur hexafluoride discharges. Furthermore, plasma nanotexturing imposed on microstructured polymer surfaces leads to dual-scale topographies exhibiting robust superhydrophobicity, as has been demonstrated for PDMS (49), parylene (50), SU-8 (51), and Si surfaces (47). Recently, there is an emerging demand to manufacture not only water but also oil repellant (i.e. amphiphobic) surfaces. Latest reports show that careful control of the geometry, slope, and undercut of micro and nanostructures on a surface allows a superhydrophobic surface to become oleophobic or superoleophobic (52) (53) (54). We are currently investigating this possibility for plasma nanotextured surfaces with impressive results.

There is a large need for superhydrophobic outdoor surfaces such as panels, windows, photovoltaic cells etc, but there exist numerous methods for manufacturing such surfaces. A cost analysis has to be done for a particular application. Low-pressure plasma technology needs vacuum processing, which increases the cost, and may make the technology less competitive for low-cost products. However, if other properties are desired in addition to superhydrophobicity, such as antireflectivity, then plasma technology can be competitive. 


\subsection{Control of optical properties of surfaces}

Reduction of surface reflectivity, with simultaneous preservation of the optical transparency is often a requirement for many surfaces, such as windows and photovoltaic cells. In other cases roughening is required so as to reduce both reflectivity and transparency. Plasmas are ideal for both applications. Several reports have appeared on this subject and patents also exist $(43,55)(8)$. However, the key here is how to control the nanotexture in order to reduce reflectance for specific wavelength range. Figure $9 \mathrm{~b}$ shows that reflectivity is indeed reduced significantly by plasma nanotexturing an organic polymer (9). . For short etch times the surface remains transparent, while for longer etch times it becomes milky. As an alternative to plasma nanotexturing, either plasma organization followed by plasma etching, or some other self-organization technique combined with plasma etching may allow full control. Indeed, nanosphere lithography followed by plasma etching has been recently proposed for antireflective and superhydrophobic surface fabrication (56).

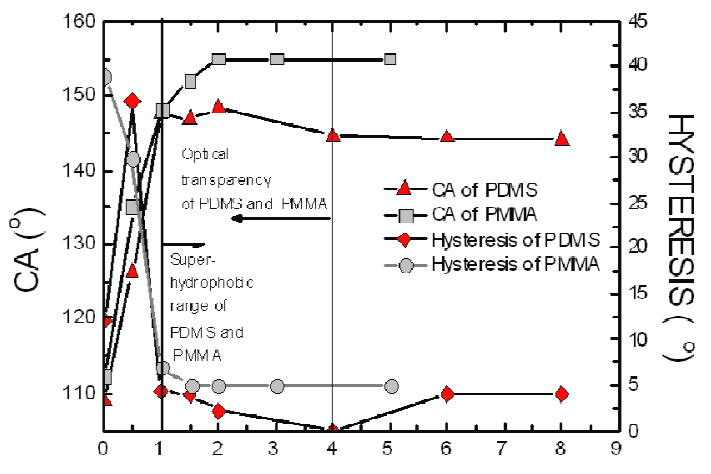

(a)

ETCHING TIME (min)

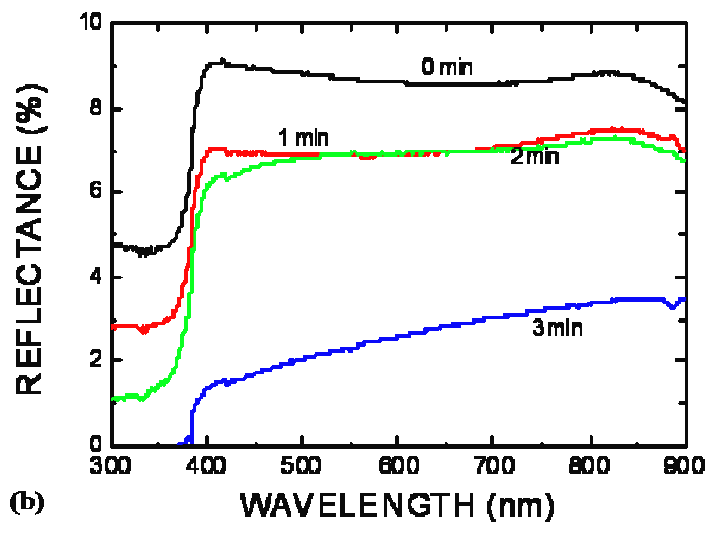

Figure 9. (a) CA and CA hysteresis versus etching time for PDMS and PMMA. The evolution of superhydrophobicity and the process window for optical transparency are also indicated. (b) Reflection spectra (at $6^{\circ}$ ) of 2mm PMMA substrates before and after 1, 2, 3 min $\mathrm{O}_{2}$ plasma processing on ONE side of the polymer plate only)(9).

\subsection{Polymeric and Silicon Microfluidic Fabrication and modification}

While for open surfaces plasma technology is in competition with other more "chemical" technologies, it is very appropriate for MEMS fabrication (57-59) and surface modification. For polymeric microfluidics plasma technology is of course in competition with injection molding and hot embossing. Nevertheless, the implementation of plasma treatment of microfluidics presents some unique merits in that:

(i) plasma etching is an inherently mass production technique,

(ii) the polymer is treated while being in its solid state,

(iii) channel formation is performed close to room temperature (cold-plasma),

(iv) within the same plasma reactor several surface physicochemical and mechanical properties (wetability, hardness etc) may be modified, towards the requirements of the specific application,

(v) master fabrication is not needed, hence using only one lithography step devices of different depths may be manufactured.

(vi) The high surface area of nanotextured polymers may be used for chromatographic separations, or as reaction sites in a lab-on-a-chip.(58, 59)

(vii) Oxygen nanotextured polymeric microfluidics are stable-in-time hydrophilic microchannels, which show capillary pumping. Fluorocarbon deposition through a stencil mask on such microchannels may create 
hydrophobic valve areas. Thus, pumping and valving through such microfluidic networks is possible due to plasma technology.

An illustration of the above concepts is shown schematically in figure 10 which shows capillary pumping and hydrophobic valving on chip.

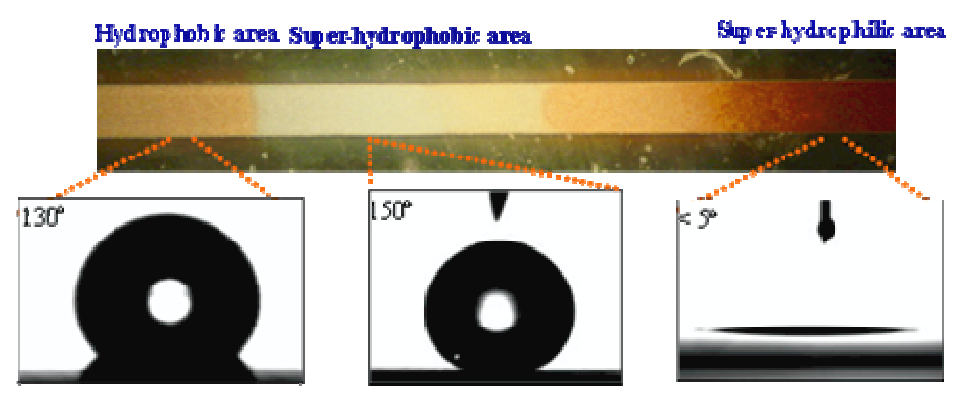

Figure 10. Three types of surfaces in a microchannel with different wetting properties (see the water contact angle on the hydrophobic, superhydrophobic and super hydrophilic stripes in the microchannel inner surface). The superhydrophobic stripe functions as a passive valve preventing capillary pumping of fluid from one superhydrophilic area to another (59)

\subsection{Protein adsorption control}

Protein microarrays are used for probing the expression of protein function. Typically polymeric substrates such as Polysterene are used and proteins are deposited with a nanoplotter. There are efforts to increase the amount of protein on each spot, and thus the fluorescence intensity of the spot, as well as reduce the size of the spot and increase the array density. Plasma nanotexturing of polymers has been proven to increase protein adsorption by a factor of 3-6 times compared to a flat substrate, mainly due to the higher surface area (60), (61). This could lead to a method of texturing surfaces as substrates for high quality, high intensity microarrays. Figure 11 illustrates the concept of high intensity microarray (62). It should be noted that adsorption of protein is selectively taking place only in the nearly hydrophobic $\left(\mathrm{CA} \sim 70^{\circ}\right)$ oxygen plasma etched and subsequently aged-in-time polymer, while it is suppressed in the superhydrophobic areas $\left(\mathrm{CA} \sim 150^{\circ}\right)$, thus permitting local control of protein adsorption on microchannel walls by local control of wetting properties, as we will soon report. Finally, plasma processing can be used for selective protein adsorption on specific substrates and for protein microarray fabrication(63), based on the selective chemical modification of surfaces in plasmas.

It should also be noted that nanotexturing permits control of cell growth on the surface as recently discussed in several reports $(64,65)$
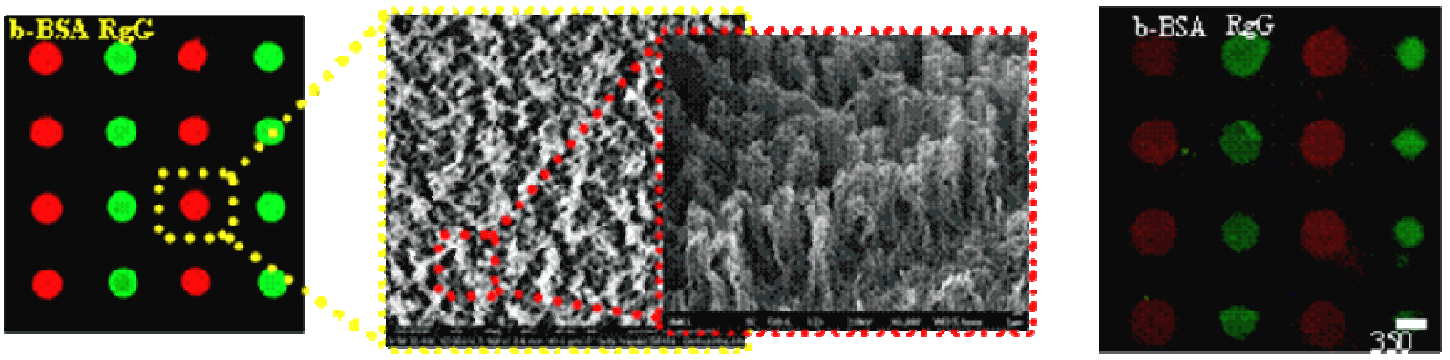

Figure 11. Fluorescence image of b-BSA and RgG spots microarray deposited by a nanoplotter on 20 min $\mathrm{O}_{2}$ plasma treated highly porous PMMA surface. The fluorescence from a flat PMMA plate is also shown on the right for comparison. (62)

\subsection{Fabrication of organized nanocolumn arrays and Silicon nanoimprint stamps}

Plasma directed organization combined with plasma etching may be used for production of moderately ordered silicon nanocolumns. Today this may be accomplished either by electron beam lithography and plasma etching (but this is a costly procedure), or colloidal nanoparticle lithography $(24,26,66)$ and plasma etching (low cost but not uniform on large areas), or block-copolymer self-assembly $(25,27)$ and plasma etching (a time 
consuming process). Thus, plasma directed assembly especially if combined with order enhancement techniques (graphoepitaxy) may become a promising alternative. Silicon nanopillar arrays may be used as nanoiprint masks for organic polymers or organic photovoltaics to permit nanostructuring of such materials and thus enhanced efficiency (67) . Work in this direction is already in progress in our team.

\section{Outlook}

Perhaps the biggest problem of plasma technology is the variability from one reactor system to another and the need to recalibrate processes, when one changes etching system. Plasma nanotexturing / nanoassembly and plasma directed organization being plasma - wall interaction phenomena add to this variability and may provoke skepticism as to the future of this technology. The answer to this challenge will be the design of systems with controlled and adjustable sputtering / deposition. This may be accomplished by a) eliminating sputtering from walls and introducing additional sputtering targets in the system, b) allowing control of wall sputtering, c) eliminating wall sputtering and allowing for gas-phase deposition during etching. Such solutions demand design of new plasma reactors with embedded or controlled sputtering / deposition sources in close collaboration with equipment manufacturers. The understanding of plasma-surface interactions necessitates also modeling and simulation tools to aid the design of better plasma systems and processes.

\section{Acknowledgments}

Financial support through various European and National projects is acknowledged, such as Nanoplasma, PENED 03ED202, MD3, Nanotolife, and others. Dr Arun Kumar is kindly acknowledged for the experiments and SEM images for PMMA films, and Mr Athanasios Smyrnakis for providing sketches of the plasma reactor. Dr Nikos Vourdas, who was the first in the group to discover and study plasma directed organization is kindly acknowledged for his early work. Oxford Instruments Plasma Technology and especially Andy Goodyear and Mike Cooke are kindly acknowledged for the experiments done in OIPT in their new plasma source during the course of the Nanoplasma EU project. Adixen-Alcatel is kindly acknowledged for kind discussions and support for the equipment operation. AFM images were processed using the Software WSxM(36)

1. Vourdas N, Tserepi A, Gogolides E. Nanotextured super-hydrophobic transparent poly(methyl methacrylate) surfaces using high-density plasma processing. Nanotechnology. 2007 Mar 28;18(12):125304.

2. Tserepi AD, Vlachopoulou ME, Gogolides E. Nanotexturing of poly(dimethylsiloxane) in plasmas for creating robust super-hydrophobic surfaces. Nanotechnology. 2006 Aug 14;17(15):3977-83.

3. Tserepi A, Gogolides E, Misiakos K, Vlachopoulou M-E, Vourdas N, inventors; Method for the fabrication of high surface area ratio and high aspect ratio surfaces on substrates International Application No PCT/GR2006/000011 Priority Number GR 20050100473. 2005.

4. Roach P, Shirtcliffe NJ, Newton MI. Progess in superhydrophobic surface development. Soft Matter. 2008;4(2):224.

5. Crick CR, Parkin IP. Preparation and Characterisation of Super-Hydrophobic Surfaces. Chemistry - A European Journal. 2010;16(12):3568-88.

6. Bhushan B, Jung YC. Natural and biomimetic artificial surfaces for superhydrophobicity, self-cleaning, low adhesion, and drag reduction. Progress in Materials Science. 2011;56(1):1-108.

7. Jansen HV, de Boer MJ, Unnikrishnan S, Louwerse MC, Elwenspoek MC. Black silicon method: X. A review on high speed and selective plasma etching of silicon with profile control: an in-depth comparison between Bosch and cryostat DRIE processes as a roadmap to next generation equipment. J Micromech Microeng. 2009;19(3):033001. 
8. Kaless A, Schulz U, Munzert P, Kaiser N. NANO-motheye antireflection pattern by plasma treatment of polymers. Surface and Coatings Technology. 2005;200(1-4):58-61.

9. Gogolides E, Vlachopoulou M, Tsougeni K, Vourdas N, Tserepi A. Micro and nano structuring and texturing of polymers using plasma processes: Potential manufacturing applications. International Journal of Nanomanufacturing. 2010;6(1-4):152-63.

10. Gogolides E, Constantoudis V, Patsis GP, Tserepi A. A review of line edge roughness and surface nanotexture resulting from patterning processes. Microelectron Eng. 2006 AprSep;83(4-9):1067-72.

11. Seeger K, Palmer RE. Fabrication of silicon cones and pillars using rough metal films as plasma etching masks. Appl Phys Lett. 1999;74(11):1627-9.

12. Levchenko I, Huang SY, Ostrikov K, Xu S. Silicon on silicon: self-organized nanotip arrays formed in reactive Ar+H2plasmas. Nanotechnology. 2010;21(2):025605.

13. Xu S, Levchenko I, Huang SY, Ostrikov K. Self-organized vertically aligned singlecrystal silicon nanostructures with controlled shape and aspect ratio by reactive plasma etching. Appl Phys Lett. 2009;95(11):111505.

14. Tam E, Levchenko I, Ostrikov K. Deterministic shape control in plasma-aided nanotip assembly. J Appl Phys. 2006 Aug 1;100(3):036104.

15. Levchenko I, Ostrikov K. Nanostructures of various dimensionalities from plasma and neutral fluxes. J Phys D: Appl Phys. 2007 Apr 21;40(8):2308-19.

16. Hsu CH, Lo HC, Chen CF, Wu CT, Hwang JS, Das D, et al. Generally applicable self-masked dry etching technique for nanotip array fabrication. Nano Letters. 2004;4(3):4715.

17. Park CK, Kim HT, Kim DY, Lee NE. Formation of silicon nitride nanopillars in dualfrequency capacitively coupled plasma and their application to Si nanopillar etching. J Vac Sci Technol A. 2007;25(4):1073-7.

18. Gharghi M, Sivoththaman S. Formation of nanoscale columnar structures in silicon by a maskless reactive ion etching process. J Vac Sci Technol A. 2006;24(3):723-7.

19. Zheng J, Yang R, Xie L, Qu J, Liu Y, Li X. Plasma-Assisted Approaches in Inorganic Nanostructure Fabrication. Advanced Materials. 2010;22(13):1451-73.

20. Levchenko I, Ostrikov K, Diwan K, Winkler K, Mariotti D. Plasma-driven selforganization of Ni nanodot arrays on Si(100). Appl Phys Lett. 2008;93(18):183102.

21. Ostrikov K. Plasma nanoscience: From nature's mastery to deterministic plasmaaided nanofabrication. Ieee T Plasma Sci. 2007 Apr;35(2):127-36.

22. Bowden N, Brittain S, Evans AG, Hutchinson JW, Whitesides GM. Spontaneous formation of ordered structures in thin films of metals supported on an elastomeric polymer. Nature. 1998 May 14;393(6681):146-9.

23. Tsougeni K, Boulousis G, Gogolides E, Tserepi A. Oriented spontaneously formed nano-structures on poly(dimethylsiloxane) films and stamps treated in O-2 plasmas. Microelectron Eng. 2008 May-Jun;85(5-6):1233-6.

24. Boal AK, Ilhan F, Derouchey JE, Thurn-Albrecht T, Russell TP, Rotello VM. Selfassembly of nanoparticles into structured spherical and network aggregates. Nature. 2000;404(6779):746-8.

25. Park C, Yoon J, Thomas EL. Enabling nanotechnology with self assembled block copolymer patterns. Polymer. 2003;44(22):6725-60.

26. Hulteen JC, Van Duyne RP. Nanosphere lithography: A materials general fabrication process for periodic particle array surfaces. J Vac Sci Technol A. 1995;13(3):1553-8.

27. Ting YH, Park SM, Liu CC, Liu XS, Himpsel FJ, Nealey PF, et al. Plasma etch removal of poly(methyl methacrylate) in block copolymer lithography. J Vac Sci Technol B. 2008 Sep-Oct;26(5):1684-9.

28. Gogolides E, Tserepi A, Constantoudis V, Vourdas N, Boulousis G, Vlachopoulou ME, et al., inventors; Method for the fabrication of periodic structures on polymers using plasma processes International Application No PCT/GR2009/000039 Priority Number GR 20080100404. 2008. 
29. Vourdas N, Kontziampasis D, Kokkoris G, Constantoudis V, Goodyear A, Tserepi A, et al. Plasma directed assembly and organization: bottom-up nanopatterning using top-down technology. Nanotechnology. 2010 Feb 26;21(8):085302.

30. Frost F, Ziberi B, Hoche T, Rauschenbach B. The shape and ordering of selforganized nanostructures by ion sputtering. Nucl Instrum Methods B. 200410 June 2003 through 13 June 2003;216(1-4):9-19.

31. Frost F, Ziberi B, Schindler A, Rauschenbach B. Surface engineering with ion beams: From self-organized nanostructures to ultra-smooth surfaces. Appl Phys A. 2008;91(4):551-9.

32. Gago R. Self-organized surface nanopatterning by ion beam sputtering in Toward Functional Nanomaterials. In: Wang ZM, editor. Lecture Notes in Nanoscale Science and Technology: Springer; 2009.

33. Kokkoris G, Constantoudis V, Angelikopoulos P, Boulousis G, Gogolides E. Dual nanoscale roughness on plasma-etched $\mathrm{Si}$ surfaces: Role of etch inhibitors. Phys Rev B. 2007;76(19):193405.

34. Engelmann S, Bruce RL, Weilnboeck F, Oehrlein GS, Nest D, Graves DB, et al. Dependence of Polymer Surface Roughening Rate on Deposited Energy Density During Plasma Processing. Plasma Process Polym. 2009;6(8):484-9.

35. Tsougeni K, Vourdas N, Tserepi A, Gogolides E, Cardinaud C. Mechanisms of Oxygen Plasma Nanotexturing of Organic Polymer Surfaces: From Stable Super Hydrophilic to Super Hydrophobic Surfaces. Langmuir. 2009 Oct 6;25(19):11748-59.

36. Horcas I, Fernandez R, Gomez-Rodriguez JM, Colchero J, Gomez-Herrero J, Baro AM. WSXM: A software for scanning probe microscopy and a tool for nanotechnology. Review of Scientific Instruments. 2007 Jan;78(1):-.

37. Martin M, Cunge G. Surface roughness generated by plasma etching processes of silicon. Journal of Vacuum Science \& Technology B: Microelectronics and Nanometer Structures. 2008;26(4):1281.

38. Boulousis G, Constantoudis V, Kokkoris G, Gogolides E. Formation and metrology of dual scale nano-morphology on SF6 plasma etched silicon surfaces. Nanotechnology. 2008 Jun 25;19(25):-.

39. Ramos R, Cunge G, Joubert O, Sadeghi N, Mori M, Vallier L. Plasma/reactor walls interactions in advanced gate etching processes. Thin Solid Films. 2007;515(12):4846-52.

40. Pelliccione M, Karabacak T, Gaire C, Wang GC, Lu TM. Mound formation in surface growth under shadowing. Phys Rev B. 2006;74(12):125420.

41. Ogawa K, Soga M, Takada Y, Nakayama I. Development of a transparent and ultrahydrophobic glass plate. Japanese Journal of Applied Physics, Part 2: Letters. 1993;32(4 B).

42. Youngblood JP, McCarthy TJ. Ultrahydrophobic polymer surfaces prepared by simultaneous ablation of polypropylene and sputtering of poly(tetrafluoroethylene) using radio frequency plasma. Macromolecules. 1999 Oct 5;32(20):6800-6.

43. Di Mundo R, De Benedictis V, Palumbo F, d'Agostino R. Fluorocarbon plasmas for nanotexturing of polymers: A route to water-repellent antireflective surfaces. Applied Surface Science. 2009;255(10):5461-5.

44. Milella A, Di Mundo R, Palumbo F, Favia P, Fracassi F, d'Agostino R. Plasma Nanostructuring of Polymers: Different Routes to Superhydrophoblicity. Plasma Process Polym. 2009 Jul 18;6(6-7):460-6.

45. Di Mundo R, Palumbo F, d'Agostino R. Nanotexturing of polystyrene surface in fluorocarbon plasmas: From sticky to slippery superhydrophobicity. Langmuir. 2008 May 6;24(9):5044-51.

46. Favia P, Cicala G, Milella A, Palumbo F, Rossini R, d'Agostino R. Deposition of super-hydrophobic fluorocarbon coatings in modulated RF glow discharges. Surf Coat Tech. 2003 Jun 2;169:609-12.

47. Shieh J, Hou FJ, Chen YC, Chen HM, Yang SP, Cheng CC, et al. Robust Airlike Superhydrophobic Surfaces. Advanced Materials. 2010 Feb 2;22(5):597-+. 
48. Han Z, Tay B, Tan C, Shakerzadeh M, Ostrikov K. Electrowetting control of Cassieto-Wenzel transitions in superhydrophobic carbon nanotube-based nanocomposites. ACS Nano. 2009;3(10):3031-6.

49. Cortese B, D'Amone S, Manca M, Viola I, Cingolani R, Gigli G. Superhydrophobicity due to the hierarchical scale roughness of PDMS surfaces. Langmuir. 2008 Mar 18;24(6):2712-8.

50. Chen MH, Hsu TH, Chuang YJ, Tseng FG. Dual hierarchical biomimic superhydrophobic surface with three energy states. Appl Phys Lett. 2009 Jul 13;95(2):-

51. Marquez-Velasco J, Vlachopoulou ME, Tserepi A, Gogolides E. Stable superhydrophobic surfaces induced by dual-scale topography on SU-8. Microelectron Eng. 2010 May-Aug;87(5-8):782-5.

52. Wang C-F, Chiou S-F, Ko F-H, Chou C-T, Lin H-C, Huang C-F, et al. Fabrication of Biomimetic Super-Amphiphobic Surfaces Through Plasma Modification of Benzoxazine Films. Macromolecular Rapid Communications. 2006;27(5):333-7.

53. Tuteja A, Choi W, Ma M, Mabry JM, Mazzella SA, Rutledge GC, et al. Designing Superoleophobic Surfaces. Science. 2007;318(5856):1618-22.

54. Liu M, Wang S, Wei Z, Song Y, Jiang L. Bioinspired Design of a Superoleophobic and Low Adhesive Water/Solid Interface. Advanced Materials. 2009;21(6):665-9.

55. Wang Y, Lu N, Xu H, Shi G, Xu M, Lin X, et al. Biomimetic corrugated silicon nanocone arrays for self-cleaning antireflection coatings. Nano Research. 2010;3(7):520-7.

56. Li Y, Zhang J, Zhu S, Dong H, Jia F, Wang Z, et al. Bioinspired Silica Surfaces with Near-Infrared Improved Transmittance and Superhydrophobicity by Colloidal Lithography. Langmuir. 2010;26(12):9842-7.

57. Rossier JIS, Vollet C, Carnal A, Lagger Gg, Gobry Vr, Girault HH, et al. Plasma etched polymer microelectrochemical systems. Lab Chip. 2002;2(3):145.

58. Nabesawa H, Hitobo T, Wakabayashi S, Asaji T, Abe T, Seki M. Polymer surface morphology control by reactive ion etching for microfluidic devices. Sensors and Actuators B: Chemical. 2008;132(2):637-43.

59. Tsougeni K, Papageorgiou D, Tserepi A, Gogolides E. "Smart'" polymeric microfluidics fabricated by plasma processing: controlled wetting, capillary filling and hydrophobic valving. Lab Chip. 2010;10(4):462-9.

60. Vlachopoulou ME, Petrou PS, Kakabakos SE, Tserepi A, Gogolides E. High-aspectratio plasma-induced nanotextured poly(dimethylsiloxane) surfaces with enhanced protein adsorption capacity. J Vac Sci Technol B. 2008 Nov;26(6):2543-8.

61. Tsougeni K, Petrou PS, Tserepi A, Kakabakos SE, Gogolides E. Nano-texturing of poly(methyl methacrylate) polymer using plasma processes and applications in wetting control and protein adsorption. Microelectron Eng. 2009 Apr-Jun;86(4-6):1424-7.

62. Tsougeni K, Tserepi A, Constantoudis V, Gogolides E, Petrou PS, Kakabakos SE. Plasma Nanotextured PMMA Surfaces for Protein Arrays: Increased Protein Binding and Enhanced Detection Sensitivity. Langmuir. 2010 Sep 7;26(17):13883-91.

63. Bayiati P, Malainou A, Matrozos E, Tserepi A, Petrou PS, Kakabakos SE, et al. Highdensity protein patterning through selective plasma-induced fluorocarbon deposition on $\mathrm{Si}$ substrates. Biosensors and Bioelectronics. 2009;24(10):2979-84.

64. Gristina R, D'Aloia E, Senesi GS, Milella A, Nardulli M, Sardella E, et al. Increasing cell adhesion on plasma deposited fluorocarbon coatings by changing the surface topography. Journal of Biomedical Materials Research Part B: Applied Biomaterials. 2009;88B(1):139-49. 65. Sardella E, Detomaso L, Gristina R, Senesi GS, Agheli H, Sutherland DS, et al. Nano-Structured Cell-Adhesive and Cell-Repulsive Plasma-Deposited Coatings: Chemical and Topographical Effects on Keratinocyte Adhesion. Plasma Process Polym. 2008;5(6):54051.

66. Zhang J, Li Y, Zhang X, Yang B. Colloidal Self-Assembly Meets Nanofabrication: From Two-Dimensional Colloidal Crystals to Nanostructure Arrays. Advanced Materials. 2010;22(38):4249-69. 
67. Cheyns D, Vasseur K, Rolin C, Genoe J, Poortmans J, Heremans P. Nanoimprinted semiconducting polymer films with $50 \mathrm{~nm}$ features and their application to organic heterojunction solar cells. Nanotechnology. 2008 Oct 22;19(42):-.

*corresponding author e-mail: evgog@imel.demokritos.gr 